\title{
Microbiological, antioxidant and lipoxygenase-1 inhibitory activities of fruit extracts of chosen Rosaceae family species
}

\author{
Andrzej B. Hendrich ${ }^{1, A, B, D-F}$, Paulina Strugała $2, B, C, E, F$, Anna Dudra ${ }^{2, B}$, Alicja Z. Kucharska ${ }^{3, B, D, E}$, Anna Sokół-Łętowska, $3,0, \mathrm{D}, \mathrm{E}$, \\ Dorota Wojnicz, ${ }^{1, B, B, D-F}$, Agnieszka Cisowska ${ }^{1, B, D}$, Zbigniew Sroka ${ }^{4, B}$, Janina Gabrielska ${ }^{2, A, D-F}$ \\ ${ }^{1}$ Department of Biology and Medical Parasitology, Wroclaw Medical University, Poland \\ ${ }^{2}$ Department of Physics and Biophysics, Wroclaw University of Environmental and Life Sciences, Poland \\ ${ }^{3}$ Department of Fruit, Vegetable and Cereal Technology, Wroclaw University of Environmental and Life Sciences, Poland \\ ${ }^{4}$ Department of Pharmacognosy and Herbal Medicines, Wroclaw Medical University, Poland \\ A - research concept and design; $\mathrm{B}$ - collection and/or assembly of data; $\mathrm{C}$ - data analysis and interpretation; \\ $D$ - writing the article; $E$ - critical revision of the article; $F$ - final approval of the article
}

Address for correspondence

Dorota Wojnicz

E-mail:dorota.wojnicz@umed.wroc.pl

Funding sources

The work was supported from funds on science research in 2010-2013 (National Science Centre) as a researchdevelopment project No. N N312 263638.

Conflict of interest

None declared

Received on June 26, 2019

Reviewed on December 5, 2019

Accepted on December 5, 2019

Published online on February 19, 2020

Cite as

Hendrich AB, Strugała P, Dudra A, et al. Microbiological, antioxidant and lipoxygenase-1 inhibitory activities of fruit extracts of chosen Rosaceae family species. Adv Clin Exp Med. 2020:29(2):215-224. doi:10.17219/acem/115086

DOI

10.17219/acem/115086

Copyright

Copyright by Author(s)

This is an article distributed under the terms of the

Creative Commons Attribution 3.0 Unported (CC BY 3.0)

(https://creativecommons.org/licenses/by/3.0/)

\section{Abstract}

Background. Extracts from the Rosaceae family fruits are rich in natural, biologically active polyphenols, but their antibacterial properties are still poorly understood. Therefore, we focused our research on their activity against uropathogenic Escherichia coli strains. This research also concerned the proof of their ability to reduce oxidative stress and modulate the activity of lipoxygenase-1 (LOX-1). It is well-known that plants represent a source of bioactive compounds whose antioxidant activity may be useful in protecting against oxidative damage in cells, which have been linked to the pathogenesis of many oxidative diseases.

Objectives. The study determined the biological activity of methanol (ME) and water (WE) extracts rich in polyphenols from the hawthorn (Crataegus monogyna Jacq.), dog rose (Rosa canina L.), quince (Cydonia oblonga Mill.), and Japanese quince (Chaenomeles speciosa (Sweet) Nakai).

Material and methods. The antioxidant capacity was evaluated using 1,1diphenyl-2-picrylhydrazyl (DPPH") and 2,2'-azino-bis(3-ethylbenzothiazoline-6-sulfonic acid) diammonium salt (ABTS+*) radical scavenging methods. The inhibition of liposome membrane oxidation was studied using the thiobarbituric acid reactive substances assay. Lipoxygenase-1 inhibitory activity was measured using the spectrophotometric method. Bacterial growth was determined by evaluating the number of colony forming units per milliliter (CFU/mL). Hydrophobicity was established with salt aggregation hydrophobicity test (SAT). Swimming and swarming motilities were evaluated using soft-agar plates. Production of curli fimbriae was estimated on CFA agar. The $P$ fimbriae were detected using the hemagglutination of erythrocytes. Adhesion of bacteria to human uroepithelial cells was assessed. The amount of biofilm was determined spectrophotometrically.

Results. We showed that most of these extracts are effective antioxidants and free radical scavengers, possess reasonable potential anti-inflammatory activity, reduce the adhesion of $E$. coli to uroepithelial cells, and reduce the ability of these bacteria to form biofilm.

Conclusions. The extracts examined, showing very promising biological properties, seem to be able to join the list of substances that can be used as dietary supplements aimed at preventing, for example, urinary tract infections, or as support of drug treatment in many diseases.

Key words: Rosaceae fruit extracts, antimicrobial, antioxidant, lipoxygenase-1 inhibition 


\section{Introduction}

In recent years, dozens of scientific articles containing the keywords "cranberry" and "proanthocyanidins" have been published. ${ }^{1}$ This is a consequence of the commonly known fact that many berries (not only cranberries) contain relatively large amounts of anthocyanins, ellagitannins and proanthocyanidins. ${ }^{2,3}$ This, combined with the other well-accepted facts that cranberry juice or extracts possess antibacterial properties, especially that they can reduce the risk of urinary tract infections, might result in the conclusion that the presence of anthocyanins and/or proanthocyanidins in certain plants is essential for their biological and/or antioxidant activity. ${ }^{4,5}$ To test if this conclusion is true, we have chosen for the present study the methanol (ME) and water (WE) extracts of 4 fruits of plants belonging to the Rosaceae family and (according to the preliminary chemical analysis) possessing almost none or relatively small amounts of anthocyanins/proanthocyanidins (when compared to other bioactive phenolics). The Rosaceae family was chosen because many its members have been used in folk medicine. For example, rose hips (in particular those of the dog rose) were traditionally used as anti-infectious and anti-inflammatory agents. ${ }^{6}$ Several North American First Nations have used hawthorn as a remedy against gastrointestinal disorders and respiratory problems like coughs, flu, bronchitis, and asthma, while in Chinese traditional medicine, it was used against circulatory problems, indigestion, diarrhea, and hypertension. ${ }^{7}$ On the other hand, quince was used in Italy in folk medicine for treatment of various skin diseases and in Portugal the sedative, antipyretic, antidiarrheal, and antitussive properties of quince leaves were utilized. ${ }^{8}$ In the current paper, the chemical analysis of the composition of the extract has been followed by an assessment of their antioxidant and lipoxygenase-1 (LOX-1) inhibitory (as a potential anti-inflammatory) properties and antibacterial effects exerted against Escherichia coli rods.

\section{Material and methods}

\section{Plants and extract preparation}

The raw material to study was hawthorn, dog rose, quince, and Japanese quince (J. quince). Fruits of hawthorn, dog rose and J. quince were collected in Szczytnicki Garden in Wrocław, Poland, whereas the fruits of quince were collected in the Arboretum and Institute of Physiography in Bolestraszyce, Poland. The WE and ME were prepared exactly as previously described by Sroka et al. ${ }^{9}$

\section{Determination of total phenol content and identification of components}

Total polyphenols were determined using the FolinCiocalteu method. The results were calculated as the equivalent of gallic acid (in micromoles) per gram of dry matter of the extract ( $\mu \mathrm{M} \mathrm{GAE/g} \mathrm{d.m.).}$

\section{Preparation of liposomes and induction of lipid peroxidation}

The method of lipid peroxidation assessment was described by Strugała et al. ${ }^{10}$ The lipid peroxidation level in the liposomes was measured as the concentration of a thiobarbituric acid reactive substance (TBARS). The antioxidant activity of the extracts tested was expressed with the parameters: $\mathrm{IC}_{50}{ }^{\mathrm{PC}}$ (Inhibition Concentration) $[\mathrm{mg} / \mathrm{mL}]$ and TEAA (Trolox equivalent antioxidant activity expressed in micrograms of Trolox per gram of dry matter of the extract $-\mu \mathrm{M} \mathrm{TE} / \mathrm{g} \mathrm{d}$.m.). $\mathrm{IC}_{50}{ }^{\mathrm{PC}}$ represented the amount of an antioxidant which causes $50 \%$ inhibition of phosphatidylcholine (PC) liposome peroxidation.

\section{Free-radical scavenging assay}

The free-radical scavenging activity of 1,1diphenyl-2-picrylhydrazyl $\left(\mathrm{DPPH}^{\circ}\right)$ was measured according to the method described by us in an earlier work. ${ }^{10}$ The free-radical scavenging activity of cation-radicals (2,2'-azino-bis(3ethylbenzothiazoline-6-sulfonic acid) diammonium salt $\left.\left(\mathrm{ABTS}^{+}\right)\right)$was assessed according to the method described by Re et al. ${ }^{11}$ The results are expressed as $\mu \mathrm{M}$ TE/g d.m. by reference to a standard curve.

\section{Evaluation of LOX-1 inhibition}

The inhibition of soybean lipoxygenase (Sigma-Aldrich, St. Louis, USA) by fruit extracts was tested using the procedure described by Axelrod et al. ${ }^{12}$ with modifications. The WE and ME of the plants at a concentration of $150 \mu \mathrm{g} / \mathrm{mL}$ were used. For comparative purposes, the non-steroidal anti-inflammatory agent Ibuprofen was used as a reference substance at a concentration of $0.75 \mu \mathrm{g} / \mathrm{mL}$. Reactions were carried out in $10 \mathrm{~mm}$ path-length quartz cuvettes containing, in a final volume of $2.6 \mathrm{~mL}$ : borate buffer $\mathrm{pH}$ 9.0, LOX-1 $(0.1 \mathrm{mg} / \mathrm{mL})$, the extracts tested, and $50 \mu \mathrm{M}$ linoleic acid. This mixture was incubated for $3 \mathrm{~min}$ at room temperature, prior to the measurement. Reference cuvettes (of $2.6 \mathrm{~mL}$ volume) contained sodium linoleate borate buffer and an appropriate volume of the solvent extract tested. Inhibition of LOX-1 activity was assessed through spectrophotometric monitoring of the absorbance increase at $234 \mathrm{~nm}(1 \mathrm{~min}, 2 \mathrm{~min}$ and $3 \mathrm{~min}$ after linoleic acid addition) due to formation of conjugated diene hydroperoxides during the enzymatic oxidative processes. Percentage inhibitory effect was calculated using the following formula: 


$$
\% \text { inhibition }=\frac{\Delta A_{\text {control }}-\Delta A_{\text {sample }}}{\Delta A_{\text {control }}} \cdot 100 \%
$$

where: $\Delta \mathrm{A}_{\text {control }}$ and $\Delta \mathrm{A}_{\text {sample }}$ denote the increase of absorbance after $3 \mathrm{~min}$ from substrate addition to the probe without or with the extract tested, respectively.

\section{Bacterial strain and growth conditions}

A clinical E. coli strain isolated from the urine of a patient hospitalized in the University Hospital in Wrocław was used. The E. coli stock culture was kept in the refrigerator $\left(-40^{\circ} \mathrm{C}\right)$ on a nutrient agar plate. Before each experiment, the strain was first allowed to reach room temperature, transferred to tryptic soy agar, and incubated at $37^{\circ} \mathrm{C}$ for $18 \mathrm{~h}$. Then, bacterial cells were incubated in tryptic soy broth with varying concentrations $(1,5,10,20,30,40,50$, $60,65,70,75$, and $80 \mathrm{mg} / \mathrm{mL}$ ) of ME or WE of the plants tested for $24 \mathrm{~h}$ at $37^{\circ} \mathrm{C}$. Control cultures were incubated in the absence of plant extracts.

\section{Antimicrobial activity}

The antibacterial activities of the tested fruit ME and WE were determined with the standard dilution method. After incubation with different concentrations of fruit $\mathrm{ME}$ and WE, the bacterial cells were centrifuged, washed 3 times in phosphate buffered saline (PBS), diluted, and cultured on nutrient agar plates for $18 \mathrm{~h}$ at $37^{\circ} \mathrm{C}$. The effect of the tested extracts on bacterial growth was evaluated on the basis of the number of colony forming units per milliliter $(\mathrm{CFU} / \mathrm{mL})$.

\section{Swimming and swarming motility}

Swimming and swarming motilities were evaluated using soft-agar plates according to the procedures described by Hidalgo et al. ${ }^{13}$ and Sanchez-Torres et al. ${ }^{14}$

\section{Hydrophobicity of bacterial cells}

Bacterial cell hydrophobicity was assessed with the salt aggregation hydrophobicity test (SAT) as described by Siegfried et al. ${ }^{15}$

\section{The ability to produce curli and P fimbriae}

Production of curli fimbriae was estimated by bacterial growth on CFA agar supplemented with Congo red dye as described by Rosser et al. ${ }^{16}$ Escherichia coli colonies expressing curli fimbriae are able to bind Congo red dye, so they demonstrate the red color. The P fimbriae expression was detected using the hemagglutination of $3 \%$ human erythrocytes (blood group 0) in the presence and absence of $3 \%$ (w/v) D-mannose (mannose-resistant hemagglutination), as described by Latham et al. ${ }^{17}$

\section{Adhesion of bacteria to human uroepithelial cells}

The cell adhesion assay was performed essentially as described previously. ${ }^{18}$

\section{Biofilm formation assay}

The biofilm formation assay was performed according to O'Toole and Kolter. ${ }^{19}$ After 1, 2, 3, 4, 5, 6, 7, 8, 9, and 10 days of incubation, the $\mathrm{OD}_{590}$ values of the stained biofilms were read using a microtiter plate reader. On the basis of the recorded optical densities (ODs) of bacterial biofilms, E. coli strains were divided into 4 categories: $\mathrm{OD} \leq \mathrm{ODc}$ (no biofilm producer); ODc $<\mathrm{OD} \leq 2 \times$ ODc (weak biofilm producer); $2 \times$ ODc $<$ OD $\leq 4 \times$ ODc (moderate biofilm producer); and $4 \times$ ODc $<$ OD (strong biofilm producer). ${ }^{20}$ The cut-off OD (ODc) was defined as 4 standard deviations (SD) above the mean OD of the negative control. In our study, the ODc value was 0.003 .

\section{Statistical analysis}

The results of all the experiments are given as a mean value \pm SD of 3 independent experiments. The data concerning the antioxidant and anti-inflammatory properties was compared using Duncan's multiple range test and analyzed using one-way analysis of variance (ANOVA). The differences in swimming and swarming motilities, bacterial adhesion, and biofilm formation by bacteria exposed and unexposed to fruit extracts were analyzed with a parametric t-test for independent samples using STATISTICA v. 9.0 (StatSoft, Inc., Tulsa, USA). P-values $<0.05$ were considered to be statistically significant.

\section{Results}

\section{Total polyphenol content and extract composition analysis}

The results of the total polyphenol content analysis using the Folin-Ciocalteu method of the studied extracts are presented in Table 1. Qualitative and quantitative analysis of the components present in the extracts was performed with the high-performance liquid chromatography (HPLC), and the results are presented in Table 1. As can be seen, individual extracts differed in their composition depending on the method of extraction as well as on the type of fruit. The biggest similarities can be found in the case of flavanols and flavonols that are present in $\mathrm{ME}$ of dog rose, quince and J. quince. All these preparations are relatively rich in quercetin 3-O-galactoside and quercetin 3-O-glucoside. These 2 components were also found in hawthorn ME, however, in much smaller amounts than in other extracts. On the other hand, among phenolic 
Table 1. Total polyphenol content (TPC) and main groups of phenolic compounds (flavanols and flavonols, phenolic acids, and their derivatives) of methanol (ME) and water (WE) extracts of plants studied

\begin{tabular}{|c|c|c|c|c|c|c|}
\hline \multirow{2}{*}{ Fruit } & \multicolumn{2}{|c|}{ TPC [ $\mu \mathrm{M}$ GAE/g d.m.] } & \multicolumn{2}{|c|}{ Flavanols and flavonols } & \multicolumn{2}{|c|}{ Phenolic acids and derivatives } \\
\hline & $\mathrm{ME}$ & WE & $\overline{M E}$ & $\overline{W E}$ & $\mathrm{ME}$ & WE \\
\hline Hawthorn & $58.8 \pm 1.9^{c}$ & $23.8 \pm 0.7^{d}$ & $\begin{array}{c}\text { (-)epicat }(75.0 \%) \\
\text { f-3-ol dimer }(12.0 \%) \\
\text { f-3-ol trimer }(5.7 \%) \\
\text { q-3-gal }(3.8 \%) \\
\text { q-3-glc }(1.2 \%) \\
\text { q-3-rut }(0.3 \%) \\
\text { n.i. }(2 \%)\end{array}$ & n.d. & $\begin{array}{c}\text { chlor ac (45.9\%) } \\
\text { p-coum ac }(21.1 \%) \\
\text { phenolic ac n.i. }(13.7 \%) \\
\text { neochlor ac }(8.9 \%) \\
\text { n.i. }(10.4 \%)\end{array}$ & $\begin{array}{c}\text { neochlor ac (69.4\%) } \\
\text { p-coum ac (18.0\%) } \\
\text { phenolic ac n.i. (8.0\%) } \\
\text { n.i. }(5.0 \%)\end{array}$ \\
\hline Dog rose & $46.4 \pm 2.9^{d}$ & $49.3 \pm 1.5^{\mathrm{a}}$ & $\begin{array}{l}\text { q-3-gal (35.2\%) } \\
\text { q-3-glc (64.8\%) }\end{array}$ & $\begin{array}{c}(+) \text { cat }(86.7 \%) \\
\text { procyanidin n.i. (13.3\%) }\end{array}$ & $\begin{array}{c}\text { gall ac }(45.3 \%) \\
\text { ell ac }(28.5 \%) \\
\text { der gall ac }(26.2 \%)\end{array}$ & der gall ac (100.0\%) \\
\hline Quince & $152.9 \pm 4.1^{b}$ & $37.0 \pm 1.2^{b}$ & $\begin{array}{c}\text { q-3-gal }(57.8 \%) \\
\text { q-3-glc }(15.8 \%) \\
\text { q-3-pento }(15.8 \%) \\
\text { q-3-rut }(9.1 \%) \\
\text { n.i. }(1.5 \%)\end{array}$ & $\begin{array}{l}\text { q-3-gal }(87.5 \%) \\
\text { q-3-rut }(12.5 \%)\end{array}$ & $\begin{array}{c}\text { chlor ac }(39.8 \%) \\
\text { phenolic ac n.i. }(29.9 \%) \\
\text { n.i. }(30.3 \%)\end{array}$ & $\begin{array}{c}\text { chlor ac (38.0\%) } \\
\text { phenolic ac n.i. (43.9\%) } \\
\text { n.i. }(18.1 \%)\end{array}$ \\
\hline $\begin{array}{l}\text { Japanese } \\
\text { quince }\end{array}$ & $216.5 \pm 7.2^{\mathrm{a}}$ & $30.9 \pm 1.5^{c}$ & $\begin{array}{l}\text { q-3-gal }(54.7 \%) \\
\text { q-3-glc }(18.8 \%) \\
\text { n.i. }(26.5 \%)\end{array}$ & n.d. & $\begin{array}{c}\text { chlor ac (40.1\%) } \\
\text { phenolic ac n.i. (39\%) } \\
\text { neochlor ac }(14.9 \%) \\
\text { dicaffe ac }(4.6 \%)\end{array}$ & $\begin{array}{c}\text { chlor ac }(81.4 \%) \\
\text { n.i. }(19.6 \%)\end{array}$ \\
\hline
\end{tabular}

d.m. - dry matter; GAE/g d.m. - equivalent of gallic acid (in micromoles) per gram of dry matter of the extract; (-)epicat - (-)epicatechin; (+)cat - (+)catechin; chlor ac - chlorogenic acid; der gall ac - derivatives of gallic acid; dicaffe ac - dicaffeoylquinic acid; ellg ac - ellagic acid; f-3-ol dimer - flavan-3-ol dimer; f-3-ol trimer - flavan-3-ol trimer; gall ac - gallic acid; neochlor ac - neochlorogenic acid; p-coum ac - p-coumaroquinic acid; phenolic ac - phenolic acid; q-3-gal - quercetin 3-O-galactoside; q-3-glc - quercetin 3-O-glucoside; q-3-rut - quercetin 3-O-rutinoside; q-3-pento - quercetin 3-O-pentoside; n.i. - not identified; n.d. - not determined. Different uppercase letters ( $a-d)$ within the same columns indicate significant differences at $p<0.05$ in Duncan's test.

acids, the common component for hawthorn, quince and J. quince ME, and quince and J. quince WE was chlorogenic acid, which in the case of the last extract mentioned reached the level of $81.4 \%$ contribution.

\section{Free-radical scavenging and antioxidant properties}

The results of experiments in which the antioxidant and radical scavenging properties of the extracts studied have been determined are presented in Table 2. As can be seen, both extracts of J. quince appeared to possess the strongest antioxidant properties (as determined with all tests used), and the $\mathrm{ME}$ of these fruits was also the most effective free radical scavenger (in both DPPH* and $\mathrm{ABTS}^{\bullet+}$ tests). The scavenger activity of all extracts studied is comparable to that measured by Grace et al. ${ }^{21}$ for cranberries; however, one has to keep in mind that the activities mentioned were calculated with respect to the fresh weight of the berries (not dry mass as in our case). The weakest antioxidant properties were recorded for both types of quince extracts whereas dog rose extracts were found to be the poorest free radical scavengers.

\section{Effects of the extracts on LOX-1 inhibition}

As it follows from Table 3, all extracts studied were able to inhibit soybean LOX to an extent comparable to the inhibition effects exerted by the 200 -fold smaller

Table 2. Antioxidant $\left(\mathrm{IC}_{50}{ }^{\mathrm{PC}}\right.$ ), Trolox Equivalent Antioxidant Activity (TEAA) and antiradical (DPPH; $\left.\mathrm{ABTS} \mathrm{S}^{+}\right)$activities of methanol (ME) and water (WE) extracts from fruit of the Rosaceae family

\begin{tabular}{|c|c|c|c|c|c|c|c|c|}
\hline \multirow[t]{2}{*}{ Fruit } & \multicolumn{2}{|c|}{$\begin{array}{c}\mathrm{IC}_{50}{ }^{\mathrm{PC}} \\
{[\mathrm{mg} / \mathrm{mL}]}\end{array}$} & \multicolumn{2}{|c|}{$\begin{array}{c}\text { TEAA } \\
{[\mu \mathrm{M} \text { TE/g d.m.] }}\end{array}$} & \multicolumn{2}{|c|}{$\begin{array}{c}\text { DPPH } \\
\text { [ } \mu \mathrm{M} \text { TE/g d.m.] }\end{array}$} & \multicolumn{2}{|c|}{$\begin{array}{c}\text { ABTS }^{+\cdot} \\
{[\mu \mathrm{M} \text { TE/g d.m.] }}\end{array}$} \\
\hline & ME & WE & ME & WE & ME & WE & ME & WE \\
\hline Hawthorn & $\begin{array}{l}0.148^{b} \\
\pm 0.002\end{array}$ & $\begin{array}{l}1.119^{b} \\
\pm 0.005\end{array}$ & $\begin{array}{c}80.90^{\mathrm{b}} \\
\pm 1.1\end{array}$ & $\begin{array}{l}23.80^{c} \\
\pm 0.04\end{array}$ & $\begin{array}{c}234.6^{b} \\
\pm 9.5\end{array}$ & $\begin{array}{c}103.6^{b} \\
\pm 2.5\end{array}$ & $\begin{array}{l}479.6^{b} \\
\pm 14.5\end{array}$ & $\begin{array}{c}186.2^{c} \\
\pm 2.5\end{array}$ \\
\hline Dog rose & $\begin{array}{l}0.160^{b} \\
\pm 0.035\end{array}$ & $\begin{array}{l}0.208^{c} \\
\pm 0.010\end{array}$ & $\begin{array}{c}78.40^{\mathrm{b}} \\
\pm 1.0\end{array}$ & $\begin{array}{l}55.70^{b} \\
\pm 2.70\end{array}$ & $\begin{array}{l}171.1^{c} \\
\pm 5.1\end{array}$ & $\begin{array}{l}150.7^{a} \\
\pm 3.2\end{array}$ & $\begin{array}{l}370.7^{d} \\
\pm 9.6\end{array}$ & $\begin{array}{r}365.2^{\mathrm{a}} \\
\pm 12.2\end{array}$ \\
\hline Quince & $\begin{array}{c}0.183^{a} \\
\pm 0.002\end{array}$ & $\begin{array}{r}1.792^{\mathrm{a}} \\
\pm 0.002\end{array}$ & $\begin{array}{l}65.40^{c} \\
\pm 1.10\end{array}$ & $10.90^{d} \pm 0.50$ & $\begin{array}{c}232.8^{b} \\
\pm 2.9\end{array}$ & $\begin{array}{l}111.5^{\mathrm{b}} \\
\pm 4.4\end{array}$ & $\begin{array}{r}390.5^{c} \\
\pm 17.3\end{array}$ & $\begin{array}{l}247.5^{b} \\
\pm 3.7\end{array}$ \\
\hline $\begin{array}{l}\text { Japanese } \\
\text { quince }\end{array}$ & $\begin{array}{c}0.124^{c} \\
\pm 0.040\end{array}$ & $\begin{array}{l}0.089^{d} \\
\pm 0.042\end{array}$ & $\begin{array}{l}96.76^{a} \\
\pm 3.10\end{array}$ & $\begin{array}{r}134.6^{a} \\
\pm 10.60\end{array}$ & $\begin{array}{c}275.3^{a} \\
\pm 4.4\end{array}$ & $\begin{array}{l}73.4^{c} \\
\pm 1.4\end{array}$ & $\begin{array}{l}547.7^{a} \\
\pm 35.4\end{array}$ & $\begin{array}{l}162.4^{d} \\
\pm 2.0\end{array}$ \\
\hline
\end{tabular}

Different uppercase letters $(a-d)$ within the same columns indicate significant differences at $p<0.05$ in Duncan's test. IC ${ }_{50}{ }^{P C}-$ the concentration of antioxidant which reduces peroxidation intensity of phosphatidylcholine liposomes by about $50 \%$. 
Table 3. Lipoxygenase (LOX-1) inhibitory activity (\%) of methanol (ME) and water (WE) extracts at $150 \mu \mathrm{g} / \mathrm{mL}$ and non-steroidal anti-inflammatory agent Ibuprofen at $0.75 \mu \mathrm{g} / \mathrm{mL}$

\begin{tabular}{|c|c|c|}
\hline \multirow{2}{*}{$\begin{array}{l}\text { Examined } \\
\text { substance }\end{array}$} & \multicolumn{2}{|c|}{ \% LOX-1 inhibition } \\
\hline & ME & WE \\
\hline Hawthorn & $22.6 \pm 3.4^{c}$ & $47.7 \pm 1.5^{a}$ \\
\hline Dog rose & $45.7 \pm 1.0^{a}$ & $42.8 \pm 1.5^{b}$ \\
\hline Quince & $10.3 \pm 2.3^{\mathrm{d}} \uparrow$ & $31.9 \pm 2.4^{c}$ \\
\hline Japanese quince & $39.8 \pm 1.8^{b}$ & $25.9 \pm 0.5^{d}$ \\
\hline Ibuprofen & \multicolumn{2}{|c|}{$26.1 \pm 1.6$} \\
\hline
\end{tabular}

$\uparrow$ - increase of LOX-1 activity. Different uppercase letters $(a-d)$ within the same columns indicate significant differences at $p<0.05$ in Duncan's test.

concentration of Ibuprofen. The most effective inhibitors were dog rose ME and WE and hawthorn WE; however, other extracts (with the striking exception of quince $\mathrm{ME}$ ) also showed reasonable levels of LOX-1 inhibition. Somewhat surprisingly, we found that quince ME exerted the opposite effect to that of other extracts and increased the LOX-1 activity by approx. $10 \%$.

\section{Effects of the extracts on bacterial growth}

Very low concentrations of hawthorn, dog rose, quince, and J. quince ME and WE had no effect on the survival of the bacteria (Table 4). In all cases, the values of CFU/mL were comparable to controls. In this group of extracts, the best bactericidal activity was observed for J. quince (both ME and WE). The values of $\mathrm{CFU} / \mathrm{mL}$ at concentrations from $20 \mathrm{mg} / \mathrm{mL}$ to $80 \mathrm{mg} / \mathrm{mL}$ were gradually decreased to approx. $10^{4}-10^{5}$ bacteria per milliliter. A much weaker effect was found for extracts of dog rose and quince. Both $\mathrm{ME}$ and $\mathrm{WE}$ at concentrations ranging from $20 \mathrm{mg} / \mathrm{mL}$ to $80 \mathrm{mg} / \mathrm{mL}$ slightly reduced the number of bacterial cells compared to the control. Both WE and ME of hawthorn had no impact on the survival of bacteria. For all concentrations of ME and WE used in our study, the values of $\mathrm{CFU} / \mathrm{mL}$ were comparable to the control.

\section{Effects of the extracts on E. coli swimming and swarming motility}

An analysis of the average motility zone diameters of $E$. coli incubated with the extracts studied shows that no effects on the E. coli swimming ability were exerted by either ME or WE of dog rose or quince, nor by hawthorn ME (Fig. 1). The average swimming motility zone diameters of $E$. coli rods after incubation of the cells with various concentrations of these extracts were slightly lower or comparable to the control $(30.0 \pm 2.0 \mathrm{~mm})$. Water extract of hawthorn in concentrations ranging from $40 \mathrm{mg} / \mathrm{mL}$ to $80 \mathrm{mg} / \mathrm{mL}$ reduced the swimming motility zone diameters of $E$. coli down to the value of $10.0 \pm 1.0 \mathrm{~mm}$, while in the case of lower concentrations of this extract, no such effect was found. The average swimming motility zone diameters of $E$. coli rods after incubation of the cells with various concentrations of J. quince were lower than the control $(21.0 \pm 2.0 \mathrm{~mm}$ and $17.0 \pm 1.0 \mathrm{~mm}$ for ME and WE, respectively). The swarming ability of the examined rods was strongly affected by almost all concentrations of hawthorn (both ME and WE) and dog rose ME (Fig. 2). In those cases, the average swarming zone diameter was reduced from $16.0 \pm 2.0 \mathrm{~mm}$ (control) to $7-8 \mathrm{~mm}$. Such effect was also noted for higher concentrations of quince and J. quince $\mathrm{ME}$, where the observed swarming motility zone diameters decreased to 6-7 $\mathrm{mm}$. The average swarming motility zone diameters of $E$. coli rods after incubation of the cells with

Table 4. Effect of methanol (ME) and water (WE) extracts of hawthorn, dog rose, quince, and J. quince on E. coli growth

\begin{tabular}{|c|c|c|c|c|c|c|c|c|}
\hline \multirow{3}{*}{$\begin{array}{l}\text { Plant extract } \\
\text { concentration } \\
{[\mathrm{mg} / \mathrm{mL}]}\end{array}$} & \multicolumn{8}{|c|}{ 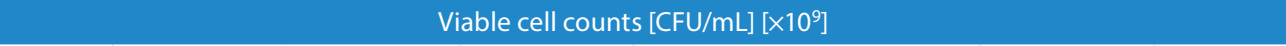 } \\
\hline & \multicolumn{2}{|c|}{ hawthorn } & \multicolumn{2}{|c|}{ dog rose } & \multicolumn{2}{|c|}{ quince } & \multicolumn{2}{|c|}{ Japanese quince } \\
\hline & ME & WE & ME & WE & ME & WE & ME & WE \\
\hline Control & \multicolumn{8}{|c|}{2.4} \\
\hline 1 & $--^{a}$ & - & - & - & - & - & 3.2 & 2.2 \\
\hline 5 & - & - & - & - & - & - & 2.2 & 1.9 \\
\hline 10 & 2.5 & 2.3 & 1.3 & 1.2 & 1.6 & 1.2 & - & - \\
\hline 20 & 1.7 & 1.8 & 1.1 & 0.67 & 0.68 & 1.2 & 0.089 & 0.027 \\
\hline 30 & 1.6 & 1.8 & 1.0 & 0.67 & 0.66 & 0.73 & 0.086 & 0.0076 \\
\hline 40 & 1.6 & 1.7 & 0.76 & 0.34 & 0.59 & 0.70 & 0.0023 & 0.0044 \\
\hline 50 & 1.5 & 1.6 & 0.62 & 0.2 & 0.57 & 0.52 & 0.00021 & 0.0012 \\
\hline 60 & 1.5 & 1.5 & 0.51 & 0.078 & 0.51 & 0.50 & 0.00021 & 0.00068 \\
\hline 65 & 1.4 & 1.2 & 0.47 & 0.073 & 0.35 & 0.49 & 0.000033 & 0.00048 \\
\hline 70 & 1.4 & 1.2 & 0.36 & 0.066 & 0.35 & 0.21 & 0.000031 & 0.00032 \\
\hline 75 & 1.3 & 1.1 & 0.34 & 0.026 & 0.30 & 0.20 & 0.000019 & - \\
\hline 80 & 1.3 & 1.1 & 0.25 & 0.020 & 0.21 & 0.14 & 0.000014 & - \\
\hline
\end{tabular}

a not tested; CFU - colony forming units. 

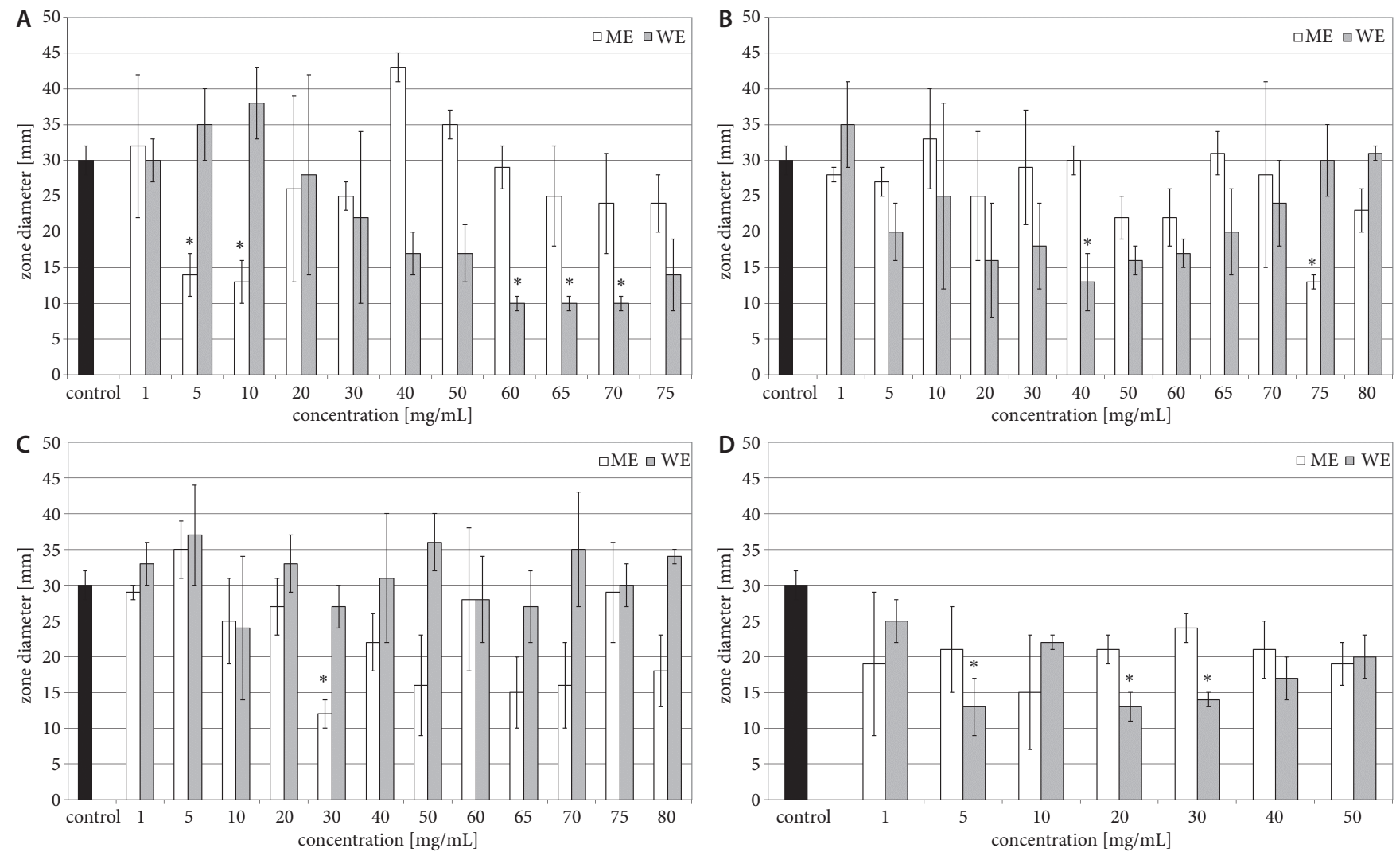

Fig. 1. Effect of methanol (ME) and water (WE) extracts of hawthorn (A), dog rose (B), quince (C), and J. quince (D) on swimming motility of E. coli strain; * $p<0.05$
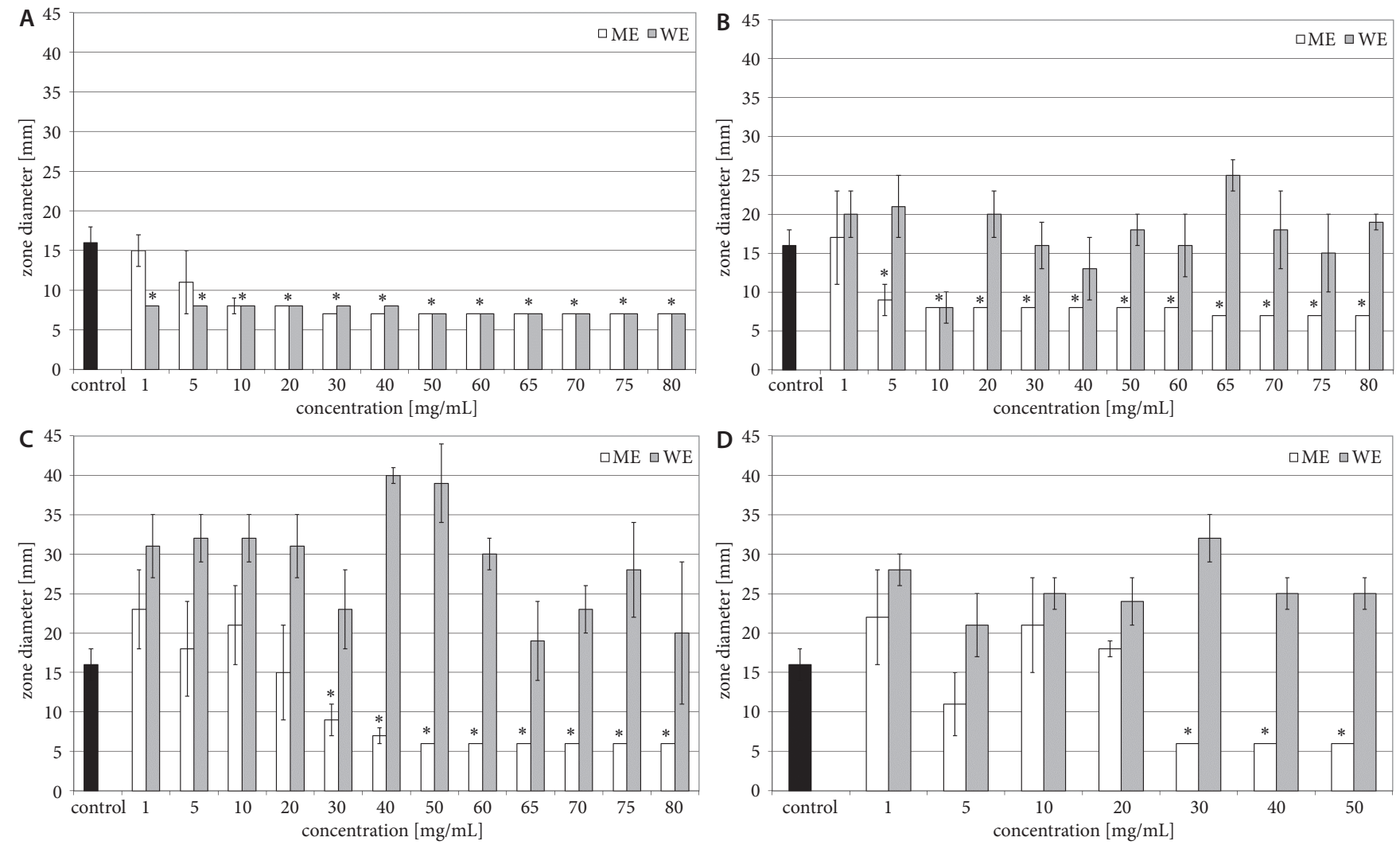

Fig. 2. Effect of methanol (ME) and water (WE) extracts of hawthorn (A), dog rose (B), quince (C), and J. quince (D) on swarming motility of E. coli strain; * $p<0.05$ 
various concentrations of quince and J. quince WE were higher than in the control $(25.0 \pm 2.0 \mathrm{~mm})$. A similar effect on the swarming ability of the $E$. coli rods examined was also shown by dog rose WE. The average swarming motility zone diameters were slightly higher or comparable to the control $(20.0 \pm 2.0 \mathrm{~mm})$.

\section{Effects of the extracts}

\section{on the hydrophobicity of bacterial} cells and on the ability to produce curli and $\mathrm{P}$ fimbriae

We observed that none of the tested plant extracts affected the hydrophobic properties of the bacterial cell surface. We also noted that the ability of $E$. coli to produce curli and $P$ fimbriae was not altered by incubation of these bacteria with all tested plant extracts.

\section{Effects of the extracts on the adhesion of bacteria to human uroepithelial cells}

The dependencies of the percentage of adhesion of bacterial cells on fruit extract concentration are shown in Fig. 3 for hawthorn, dog rose, quince, and J. quince, respectively. This figure shows that there were almost no differences in the efficacy of ME and WE; however, certain fruit extracts differed in their activity. Out of the 4 extracts studied herein, only hawthorn extract showed poor effects
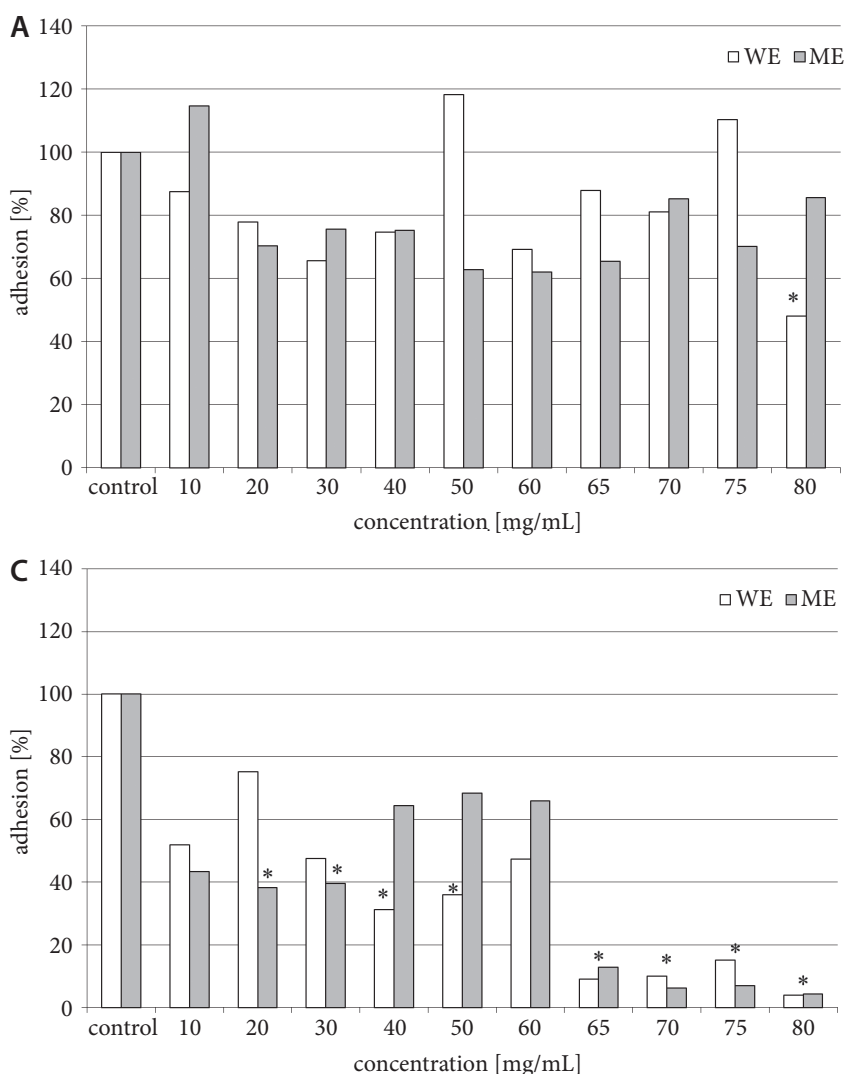

and weakly reduced adhesion of bacteria to epithelial cells (Fig. 3A), even at high concentrations $(70-80 \mathrm{mg} / \mathrm{mL})$. Much stronger effects were recorded for dog rose and quince extracts (Fig. 3B), which were able to reduce percentage of adhesion to less than $10 \%$ when used at high concentrations. The strongest effects were found for J. quince (Fig. 3D), for which a significant decrease of adhesion was recorded for concentrations exceeding $20 \mathrm{mg} / \mathrm{mL}$.

\section{Effects of the extract on biofilm formation}

The control samples of $E$. coli incubated up to 10 days in the absence of the fruit extracts studied herein have shown that the amounts of biofilm formed by these bacteria changed in time, reaching maxima on approx. the $3^{\text {rd }}$ and $8^{\text {th }}$ day of incubation (see the control bars in any panel of Fig. 4). Incubation of the bacteria with the addition of the fruit extracts studied affected the growth of biofilm within the region of the $1^{\text {st }}$ and/or $2^{\text {nd }}$ maximum, depending on the type of extract. The strongest reduction of biofilm was observed when the bacteria were incubated with WE of J. quince (Fig. 4D - note that J. quince was used at half of the concentrations used for other extracts) and quince, for which complete disappearance of the biofilm was observed during the whole time of observation. The ME of J. quince also showed strong biofilm reducing properties; however, the presence of some biofilm remains
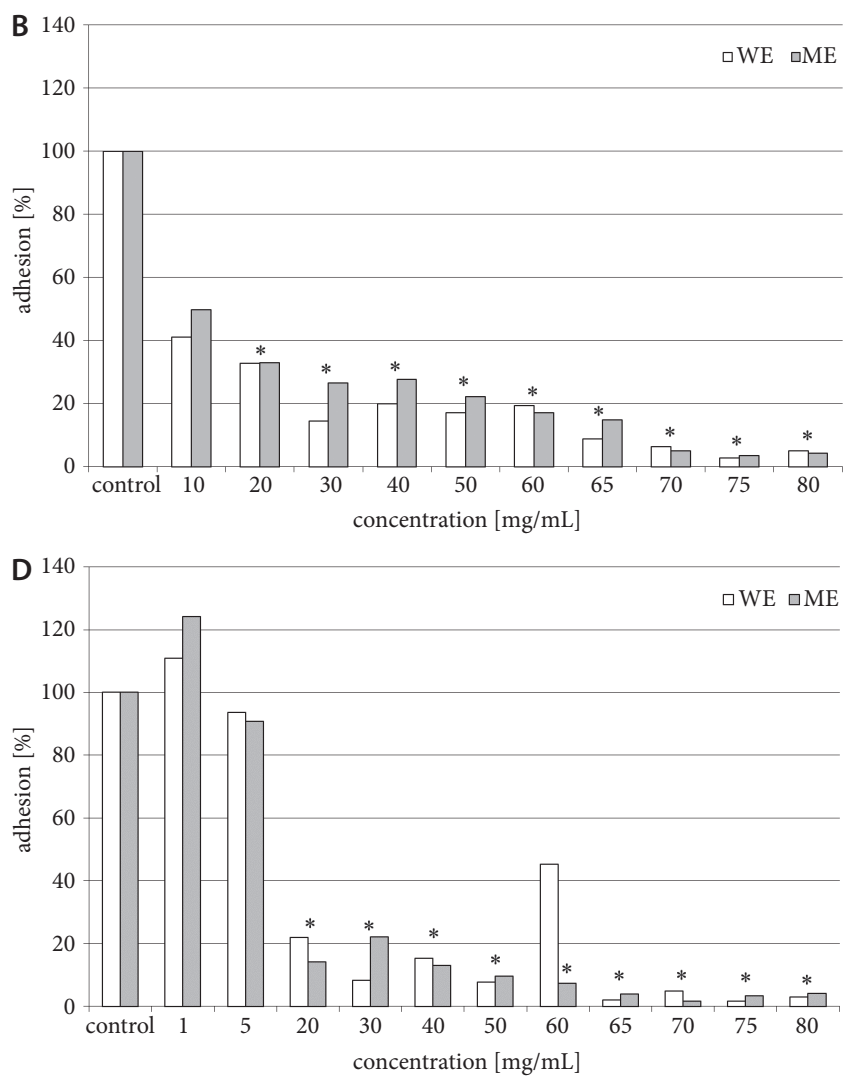

Fig. 3. Effect of water (WE) and methanol (ME) extracts of hawthorn (A), dog rose (B), quince (C), and J. quince (D) on adhesion of E. coli to human epithelial cells; ${ }^{*} p<0.05$ 

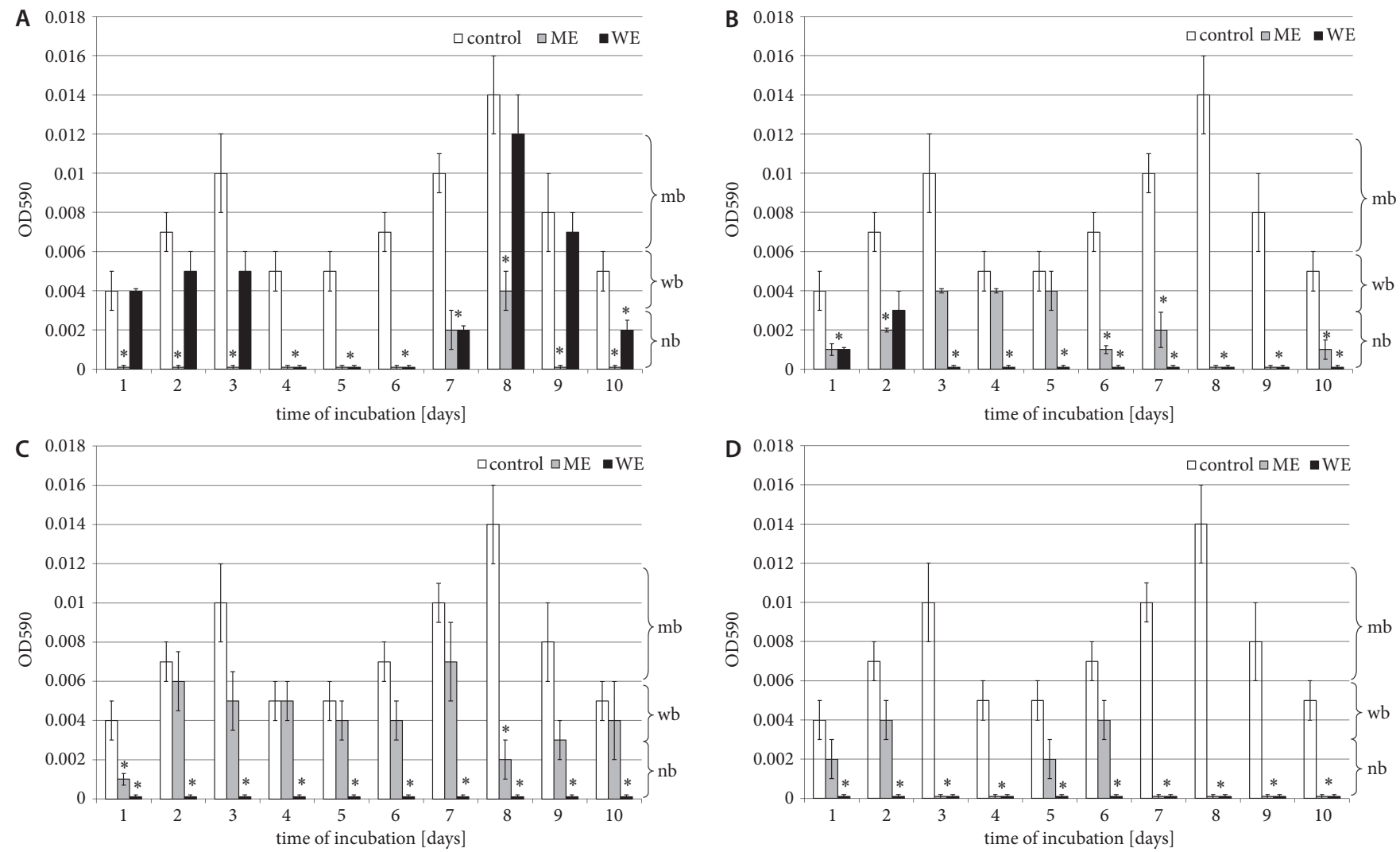

Fig. 4. Effect of water (WE) and methanol (ME) extracts of hawthorn (A), dog rose (B), quince (C), and J. quince (D) on biofilm formation ability of E. coli rods. Abbreviations used for biofilm classification: $\mathrm{nb}$ - no biofilm; wb - weak biofilm; mb - moderate biofilm. Bars exceeding mb are classified as strong biofilm; * $p<0.05$.

(classified as a weak biofilm) were recorded on the $2^{\text {nd }}$ and $6^{\text {th }}$ day of incubation. Effects comparable to those described above were also observed for hawthorn ME and dog rose WE (Fig. 4A,B). The weakest effect on the biofilm formation ability was exerted by quince $\mathrm{ME}$ (Fig. 3C), and the effects of dog rose ME can also be described as moderate.

\section{Discussion}

In recent years, much attention has been focused on plants containing various bioactive compounds which may demonstrate some pharmacological properties. ${ }^{22}$ In one aspect of our research, we used a model lipid membrane (liposomes that are a spherical bilayer) as a matrix of biological membranes. Membranes are the first target of attack by exogenous free radicals at the cellular level. Peroxidation processes of membrane lipids result in disruption of their function, which is the basis of serious diseases, e.g., atherosclerosis or diabetes. Another important aspect of the research was to check whether natural plant extracts can reduce the risk of urinary tract infections. We determined the phenolic content, antioxidant activity and potential anti-inflammatory properties of 4 plant WE and ME on one hand and assessed the effects exerted by those extracts on $E$. coli on the other hand.
The research presented herein has shown that extracts from the Rosaceae family species are rich in phenolic compounds. Quantitative/qualitative identification using HPLC showed that the components of individual extracts belong to 3 groups of phenolic compounds: flavanols, flavonols and phenolic acids. These 3 groups of phenolic compounds in hawthorn extracts, dog rose quince and J. quince were also identified by other researchers. ${ }^{23-26}$ The richest in phenolic compounds were the ME of J. quince (216.5 $\pm 7.2 \mu \mathrm{M}$ GAE/g d.m.) and quince (152.9 $\pm 4.1 \mu \mathrm{M}$ GAE/g d.m.). Chlorogenic acid was identified in all examined extracts.

Comparing the properties of the 2 types of extracts (ME vs WE), one can conclude that in most cases, ME are more effective as antioxidants as well as free radical scavengers. Statistical analysis of the abovedescribed data showed that there is no correlation between the total polyphenol content (TPC) and antioxidant properties (measured as $\mathrm{IC}_{50}{ }^{\mathrm{PC}}$ ) of the extracts studied (correlation coefficients were -0.338 and -0.273 for ME and WE, respectively). Simultaneously, some correlations were found between the TPC and radical scavenging properties of the extracts: correlation coefficients were 0.817 and 0.782 (in $\mathrm{DPPH}^{*}$ assay, ME and WE, respectively) and 0.577 and 0.927 (in $\mathrm{ABTS}^{\cdot+}$ assay, ME and WE, respectively). Bearing in mind the above statistical relations and comparing the results of the chemical analysis, it is hard to point to any strict correlation 
between the composition of the extracts and their antioxidant/protective action in relation to oxidized lipid membranes. However, we can firmly state that the ME extract of J. quince was at the top of the tables (both phenolic content and antioxidant activity). The antioxidant and antiradical activity of J. quince has been confirmed using different methods in current literature. ${ }^{27}$ Until now, to our knowledge, there are no reports related to the inhibition of the peroxidation of lipid systems mimicking the bilayer of biological membranes. Some reviews have been published that contain a wide range of information on both Chaenomeles composition and therapeutic properties. ${ }^{28,29}$ It is noteworthy that despite the relatively low but comparable TPC content of WE and ME of the dog rose, they demonstrate a high ability to inhibit lipid peroxidation and LOX-1 activity. Dog rose is also good scavenger against DPPH and ABTS mimic radicals. In mammalian cells, LOX plays a key role in the biosynthesis of a variety of bioregulatory compounds such as hydroxyeicosatetraenoic acid, leukotrienes, lipoxins, and hepoxylines. Antioxidants interact non-specifically with LOX by scavenging radical intermediates and/or reducing the active heme site. ${ }^{30}$ For example, in the work of Chen et al., it was shown that extract from Prunus campanulata Maxim, a member of the family Rosaceae, at concentrations of $25 \mu \mathrm{g} / \mathrm{mL}, 50 \mu \mathrm{g} / \mathrm{mL}$ and $100 \mu \mathrm{g} / \mathrm{mL}$ causes inhibitory activity of 15-lipoxygenase (15-LOX). ${ }^{31}$ Tumbas et al. suggest antioxidant properties of wild rose tea (as detected with $\mathrm{DPPH} \cdot$ test), presumably related to the content of vitamin $\mathrm{C}$ and flavonoid compounds. Simultaneously, the anti-proliferative properties of this tea found in several types of human cancer cells are suggested to result from the interaction with polyphenols. ${ }^{32}$ The review of Patel in various aspects sums up the research on the biological activity of fruits of the rose hip, and it indicates the research on the mechanisms of its pharmacological action. ${ }^{33}$

Anthocyanins/proanthocyanidins are often recognized as compounds that play a major role in the antibacterial activities of different fruit juices or extracts. ${ }^{1,4,34}$ Despite this, the results presented above demonstrate that many potentially useful properties can also be present in the extracts of fruits that possess a low level or none of such components. Since in our experiments we used the uropathogenic strains of $E$. coli, it seems obvious that as the most important we consider the effects exerted on those bacteria properties which are involved in the induction of urinary tract infection. Swimming and swarming motility and adhesion to the epithelial cells as well as biofilm forming ability undoubtedly belong to these properties. ${ }^{35}$ Analysis of the results obtained in our study leads to the conclusion that the most effective was the WE and ME of J. quince, which significantly reduced the swimming and swarming (except for WE) motility, adhesion to epithelial cells and biofilm formation ability of bacteria. Biofilm formation ability was reduced (to different extents) by all extracts studied and adhesion to the epithelial cell was reduced by all except hawthorn ME and WE. These last extracts have, however, significantly decreased the swarming motility of E. coli.

With the exception of haw thorn ME and WE, all extracts also showed some antibacterial properties, however, due to the moderate effect, it was not possible to determine the minimal inhibitory concentration (MIC) in the range of the extract concentrations used in our experiments. The antibacterial activity of these extracts was somehow smaller than that of cranberry extract Zuravit S-O-S ${ }^{\circledR}$, for which the MIC values were found to be $38 \mathrm{mg} / \mathrm{mL}$ or $55 \mathrm{mg} / \mathrm{mL}$, depending on the bacterial strain used in MIC determination. ${ }^{19}$ It seems worth emphasizing that apart from antibacterial properties, the fruit extracts studied also showed some anti-inflammatory properties and they appeared to be efficient free radical scavengers and antioxidant agents.

\section{Conclusions}

A significant finding in the current work is that it describes the antioxidant, antiradical, anti-inflammatory, and antimicrobial properties of polyphenol-rich extracts. The analyzed plants belonging to the Rosaceae family may be considered as valuable agents protecting in vitro the model lipid membrane against peroxidation and can reduce the risk of urinary tract infections. Japanese quince and dog rose extracts in particular, showing very promising biological properties, seem to be able to join the list of substances that can be used as dietary supplements aimed at preventing, for example, urinary tract infections, or as supportive of drug treatment in many diseases.

\section{ORCID iDs}

Andrzej B. Hendrich (1) https://orcid.org/0000-0002-5779-7781 Paulina Strugała (1) https://orcid.org/0000-0001-5949-4736 Anna Dudra (1) https://orcid.org/0000-0003-3876-5677 Alicja Z. Kucharska (1) https://orcid.org/0000-0002-2172-0408 Anna Sokół-Łętowska (1) https://orcid.org/0000-0003-2785-2791 Dorota Wojnicz (1) https://orcid.org/0000-0003-1972-1548 Agnieszka Cisowska (1) https://orcid.org/0000-0001-7405-6726 Zbigniew Sroka (10) https://orcid.org/0000-0001-6618-017X Janina Gabrielska (1) https://orcid.org/0000-0001-6125-0773

\section{References}

1. González de Llano D, Liu H, Khoo C, Moreno-Arribas MV, Bartolomé B. Some new findings regarding the antiadhesive activity of cranberry phenolic compounds and their microbial-derived metabolites against uropathogenic bacteria. J Agric Food Chem. 2019;67(8): 2166-2174.

2. Kylli P, Nohynek L, Puupponen-Pimiä R, et al. Lingonberry (Vaccinium vitis-idaea) and European cranberry (Vaccinium microcarpon) proanthocyanidins: Isolation, identification, and bioactivities. J Agric Food Chem. 2011;59(7):3373-3384.

3. Moyer RA, Hummer KE, Finn CE, Frei B, Wrolstad RE. Anthocyanins, phenolics, and antioxidant capacity in diverse small fruits: Vaccinium, rubus, and ribes. J Agric Food Chem. 2002;50(3):519-525.

4. Blumberg JB, Camesano TA, Cassidy A, et al. Cranberries and their bioactive constituents in human. Health Adv Nutr. 2013;4(6):618-632. 
5. Kim HW, Chung DH, Kim SA, Rhee MS. Synergistic cranberry juice combinations with natural-borne antimicrobials for the eradication of uropathogenic Escherichia coli biofilm within a short time. Lett Appl Microbiol. 2019;68(4):321-328.

6. Kirkeskov B, Christensen R, Bügel S, et al. The effects of rose hip (Rosa canina) on plasma antioxidative activity and C-reactive protein in patients with rheumatoid arthritis and normal controls: A prospective cohort study. Phytomedicine. 2011;18(11):953-958.

7. Edwards JE, Brown PN, Talent N, Dickinson TA, Shipley PR. A review of the chemistry of the genus Crataegus. Phytochemistry. 2012;79:5-26.

8. Oliveira AP, Pereira JA, Andrade PB, Valentão P, Seabra RM, Silva BM. Phenolic profile of Cydonia oblonga Miller leaves. J Agric Food Chem. 2007;55(19):7926-7930.

9. Sroka Z, Rządkowska-Bodalska H, Mażol I. Antioxidative effect of extracts from Erodium cicutarium L. Z Naturforsch C J Biosci. 1994;49 (11-12):881-884

10. Strugała $P$, Loi S, Bażanów B, et al. A comprehensive study on the biological activity of elderberry extract and cyanidin 3-O-glucoside and their interactions with membranes and human serum albumin. Molecules. 2018;23(10). doi:10.3390/molecules23102566.

11. Re R, Pellegrini N, Proteggente A, Pannala A, Yang M. Antioxidant activity applying an improved ABTS radical cation decolorization assay. Free Radic Biol Med. 1999;26(9-10):1231-1237.

12. Axelrod B, Cheesbrough TM, Laakso S. Lipoxygenases in soybeans. Method Enzymol. 1981;71:441-451.

13. Hidalgo G, Chan M, Tufenkji N. Inhibition of Escherichia coli CFT073 fliC expression and motility by cranberry materials. Appl Environ Microbiol. 2011;77(19):6852-6857.

14. Sanchez-Torres V, Hu H, Wood TK. GGDEF proteins Yeal, YedQ, and $Y$ fiN reduce early biofilm formation and swimming motility in Escherichia coli. Appl Microbiol Biotechnol. 2011;90(2):651-658.

15. Siegfried L, Kmetová M, Puzová H, Molokáčová M, Filka J. Virulenceassociated factors in Escherichia coli strains isolated from children with urinary tract infections. J Med Microbiol. 1994;41(2):127-132.

16. Rosser T, Dransfield T, Allison L, et al. Pathogenic potential of emergent sorbitol-fermenting Escherichia coli 0157: NM. Infect Immun. 2008;76(12):5598-5607.

17. Latham RH, Stamm WE. Role of fimbriated Escherichia coli in urinary tract infections in adult women: Correlation and localization studies. J Infect Dis. 1984;149(6):835-840.

18. Wojnicz D, Sycz Z, Walkowski S, et al. Study on the influence of cranberry extract Żuravit S-O-S ${ }^{\circledR}$ on the properties of uropathogenic Escherichia coli strains, their ability to form biofilm and its antioxidant properties. Phytomedicine. 2012;19(6):506-514.

19. O'Toole GA, Kolter R. Initiation of biofilm formation in Pseudomonas fluorescens WCS365 proceeds via multiple, convergent signaling pathways: A genetic analysis. Mol Microbiol. 1998;28(3):449-461.

20. Stepanović S, Cirković I, Ranin L, Svabić-Vlahović M. Biofilm formation by Salmonella spp. and Listeria monocytogenes on plastic surface. Lett Appl Microbiol. 2004;38(5):428-432.
21. Grace MH, Esposito D, Dunlap KL, Lila MA. Comparative analysis of phenolic content and profile, antioxidant capacity, and anti-inflammatory bioactivity in wild Alaskan and commercial Vaccinium berries. J Agric Food Chem. 2014;62(18):4007-4017.

22. Paredes-López $O$, Cervantes-Ceja ML, Vigna-Pérez $M$, HernándezPérez T. Berries: Improving human health and healthy aging, and promoting quality life: A review. Plant Foods Hum Nutr. 2010;65(3): 299-308.

23. Silva BM, Andrade PB, Ferreres F, Domingues AL, Seabra RM, Ferreira $A$. Phenolic profile of quince fruit (Cydonia oblonga Miller) (pulp and peel). J Agr Food Chem. 2002;50(16):4615-4618.

24. $\mathrm{Du} \mathrm{H}, \mathrm{Wu} J, \mathrm{Li} \mathrm{H}$, et al. Polyphenols and triterpenes from Chaenomeles fruits: Chemical analysis and antioxidant activities assessment. Food Chem. 2013;141(4):4260-4268.

25. Wenzig EM, Widowitz U, Kunert O, et al. Phytochemical composition and in vitro pharmacological activity of two rose hip (Rosa canina L.) preparations. Phytomedicine. 2008;15(10):826-835.

26. Strugała P, Gładkowski W, Kucharska AZ, Sokół-Łętowska A, Gabrielska J. Antioxidant activity and anti-inflammatory effect of fruit extracts from blackcurrant, chokeberry, hawthorn, and rosehip, and their mixture with linseed oil on a model lipid membrane. Eur J Lipid Sci Technol. 2016;118(3):461-474.

27. Tang Y, Yu X, Mi M, Zhao J, Wang J, Zhang YT. Antioxidative property and antiatherosclerotic effects of the powder processed from Chaenomelas speciosa in apoe ${ }^{-1-}$ mice. J Food Biochem. 2010;34(3): 535-548.

28. Zhang SY, Han LY, Zhang H, Xin HL. Chaenomeles speciosa: A review of chemistry and pharmacology. Biomed Rep. 2014;2(1):12-18.

29. Watychowicz K, Janda K, Jakubczyk K, Wolska J. Chaenomeles: Health promoting benefits. Rocz Panstw Zakl Hig. 2017;68(3):217-227.

30. Ajila CM, Naidu KA, Bhat SG, Prasada Rao U. Bioactive compounds and antioxidant potential of mango peel extract. Food Chem. 2007; 105(3):982-988.

31. Chen $\mathrm{CH}, \mathrm{Chan} \mathrm{HC}$, Chu YT, et al. Antioxidant activity of some plant extracts towards xanthine oxidase, lipoxygenase and tyrosinase. Molecules. 2009;14(8):2947-2958.

32. Tumbas VT, Canadanović-Brunet JM, Cetojević-Simin DD, Cetković GS, Ethilas SM, Gille L. Effect of rosehip (Rosa canina L.) phytochemicals on stable free radicals and human cancer cells. J Sci Food Agric. 2012;92(6):1273-1281.

33. Patel S. Rose hip as an underutilized functional food: Evidence-based review. Trends Food Sci Technol. 2017;63:29-38.

34. Cisowska A, Wojnicz D, Hendrich AB. Anthocyanins as antimicrobial agents of natural plant origin. Nat Prod Commun. 2011;6(1):149-156.

35. Packiavathy IA, Priya S, Pandian SK, Ravi AV. Inhibition of biofilm development of uropathogens by curcumin: An anti-quorum sensing agent from Curcuma longa. Food Chem. 2014;148:453-460. 